\title{
Erratum to: Foveola nonpeeling internal limiting membrane surgery to prevent inner retinal damages in early stage 2 idiopathic macula hole
}

Tzyy-Chang Ho • Chung-May Yang • Jen-Shang Huang • Chang-Hao Yang • Muh-Shy Chen

Published online: 22 April 2014

(C) Springer-Verlag Berlin Heidelberg 2014

Erratum to: Graefes Arch Clin Exp Ophthalmol

DOI 10.1007/s00417-014-2613-7

The Figure 5 of the original version inadvertently contained mistake. An additional square image between D and E appeared.

The correct Figure 5 is shown below:

The online version of the original article can be found at http://dx.doi.org/ 10.1007/s00417-014-2613-7.

T.-C. Ho $\cdot$ C.-M. Yang $\cdot$ J.-S. Huang $\cdot$ C.-H. Yang Department of Ophthalmology, National Taiwan University Hospital, College of Medicine, National Taiwan University,

Taipei 10002, Taiwan, Republic of China

M.-S. Chen $(\square)$

Department of Ophthalmology, Cardinal Tein Hospital, Fu Jen Catholic University, No.362, Zhongzheng Rd., Xindian Dist., New

Taipei City 231, Taiwan, Republic of China

e-mail:mschenoph@gmail.com 


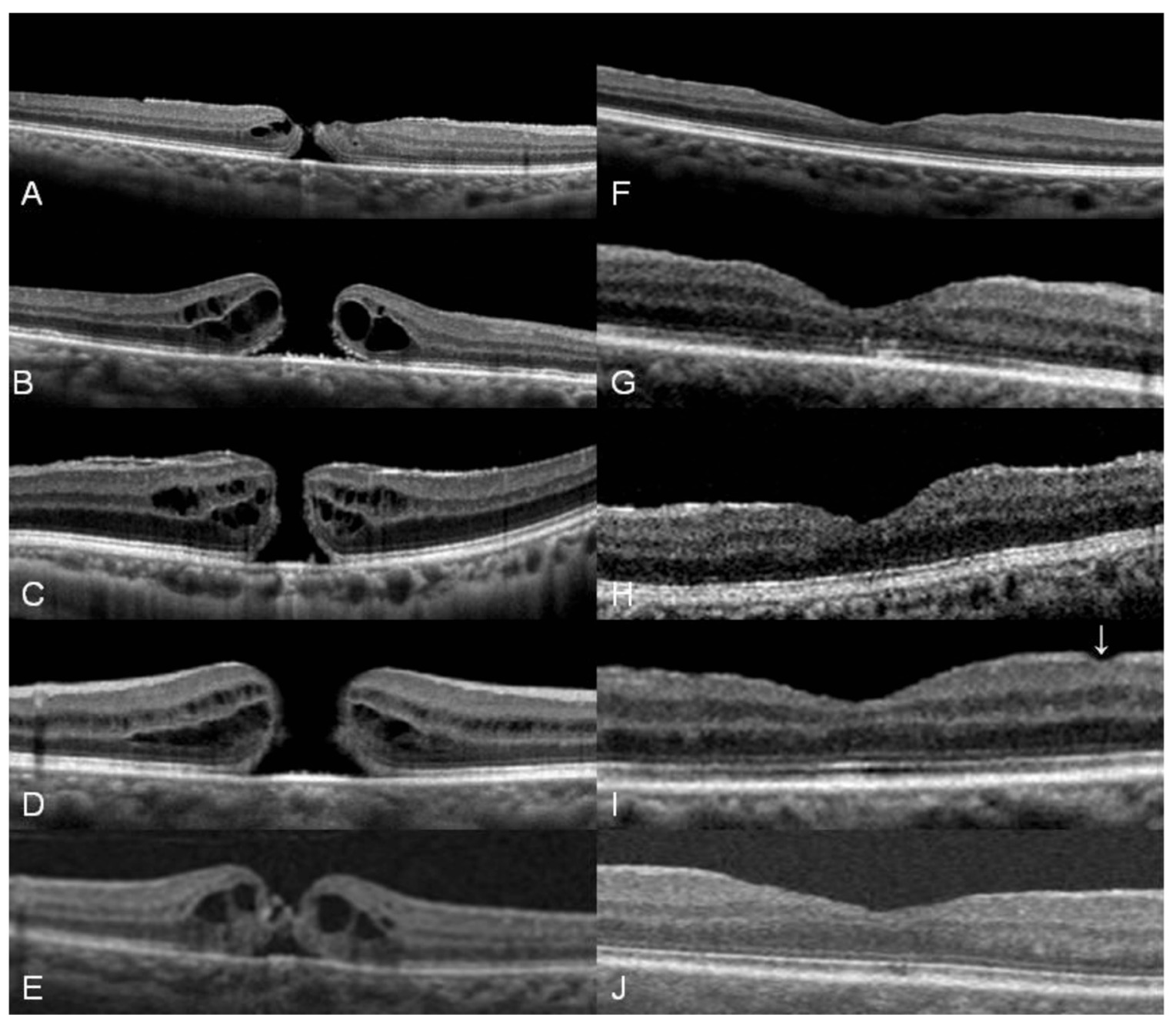

